question usually arises when a patient with communityacquired and still-unexplained pneumonia, who has a history of exposure to birds, is admitted to the hospital. To my way of thinking, the isolation guidelines of the Centers for Disease Control and Prevention (CDC) are judicious. Because the risk of nosocomial transmission is remote, conventional precautions suffice; there is no need for private quarters, a negativepressure room, masks, or the like.
If the diagnosis of psittacosis is confirmed, please be sure to report the case to your local health department.

\section{REFERENCES}

1. Harris RL, Williams TW Jr. 'Contribution to the question of pneumotyphus': a discussion of the original article by J. Ritter in 1880. Rev Infect Dis 1985;1:119-122.

2. Schachter J, Sugg N, Sung M. Psittacosis: the reservoir persists. J Infect Dis 1978;137:44-49.

3. Hughes C, Maharg P, Rosario P, et al. Possible nosocomial transmission of psittacosis. Infect Control Hosp Epidemiol 1997;18:165-168.

\title{
Dramatic Drop in AIDS Deaths
}

Gina Pugliese, RN, MS Martin S. Favero, PhD

Data presented by the $\mathrm{CDC}$ at the Fourth Conference on Retroviruses and Opportunistic Infections, held in Washington, DC, on January 25-26, 1997, indicated that deaths from AIDS in New York City had fallen approximately $50 \%$ in the past year.

Mortality from AIDS had increased steadily, from 425 deaths in 1983 to 7,102 deaths in 1994. In 1995, New York's AIDS deaths fell to 7,046, marking the first year that the AIDS death rate did not increase since the epidemic began. In 1996, deaths fell substantially, to 4,944 .

This improvement is largely attributed to new treatments such as three-drug combinations containing a protease inhibitor, which have restored people with advanced HIV infection to better health.

In New York City, says Mary Ann Chiasson, a physician in the New York City's health department "clearly, funds are also having a major effect on access to care." These new funds are for AIDS treatment provided to local governments through the Ryan White CARE Act. In 1994, New York City got $\$ 100$ million through the program, compared with $\$ 44$ million the previous year.

The experts noted that this encouraging information was about deaths, not new HIV infections or new cases of AIDS. Other researchers at the meeting presented reports indicating that the AIDS incidence among people between the ages of 13 and 25 rose approximately $17 \%$ between 1990 and 1995 . It rose $73 \%$ among women and 56\% among blacks; the greatest increase was among black heterosexual women, a reported increase of $158 \%$.

FROM: Brown D. AIDS toll falls by half in New York City. Washington Post January 25, 1997:A1. 